\title{
NECK CIRCUMFERENCE POSITIVELY RELATED WITH CENTRAL OBESITY AND OVERWEIGHT IN TURKISH UNIVERSITY STUDENTS: A PRELIMINARY STUDY
}

\author{
İsmail Özkaya', Aydın Tunçkale ${ }^{2}$ \\ 'Department of Nutrition and Dietetics, Krrklareli University Health School, Krrklareli, Turkey \\ ${ }^{2}$ Division of General Internal Medicine, Department of Internal Medicine, Cerrahpasa Medical School, Istanbul University, Istanbul, Turkey
}

\begin{abstract}
SUMMARY
Aim: According to the World Health Organization, central obesity is increasing alarmingly worldwide. Neck circumference is a relatively new method of differentiating between normal and abnormal fat distribution. The aim of this study is to determine the association between neck circumference and central obesity in young Turkish male and female university students.

Methods: A community of university students based cross-sectional study was conducted on 319 males and 838 females and investigated the association between neck circumference and other anthropometric variables by gender.

Results: In male subjects, the neck circumference revealed a positive correlation with the body mass index ( $r=0.684, p<0.01)$, waist circumference $(r=0.686, p<0.01)$ and waist/hip ratio $(r=0.534, p<0.01)$. Similarly, in female subjects neck circumference revealed a positive correlation with the body mass index $(r=0.482, p<0.01)$, waist circumference $(r=0.479, p<0.01)$ and waisthip ratio $(r=0.246, p<0.01)$.

Conclusion: Our study has demonstrated that the positive correlation between neck circumference, which is a simple and fast anthropometric measurement, and visceral obesity, is also applicable to university students.
\end{abstract}

Key words: neck circumference, waist circumference, overweight, obesity, anthropometry

Address for correspondence: İ. Özkaya, Kırklareli University, Health School, Department of Nutrition and Dietetics, 39020 Kayalı, Kırklareli, Turkey. E-mail: dytismail@hotmail.com

http://dx.doi.org/10.21101/cejph.a4555

\section{INTRODUCTION}

Obesity is a public health problem seen gradually more frequently in developed and developing countries. Along with weight gain, the fat accumulation in the body increases and causes serious illnesses. Also Turkey is a country in which the obesity problem gradually increases and the mean age at which it is seen gradually decreases.

According to the World Health Organization (WHO) 2008 data, the prevalence of obesity in Turkey has increased by $34 \%$ in men and by $21.7 \%$ in women, and according to the Turkish Diabetes Epidemiology Study (TURDEP) 2011 data, the prevalence of obesity is $31.2 \%$. Moreover, during the recent 12 years it has increased by $34 \%$ (from 32.9 to 44.2 ) in women and by $107 \%$ (from 13.2 to 27.3$)$ in men $(1,2)$. The main reasons for this rather vexing problem may be sedentary lifestyle and high-calorie nutrition. Along with the increase in obesity, especially central obesity, in Turkey, the prevalence of accompanying hypertension, metabolic syndrome, dyslipidemia, insulin resistance, prediabetes, type 2 diabetes, and cardiovascular diseases is increasing as well (3).

Different anthropometric measurements are commonly used worldwide in order to determine obesity or central obesity. These are the body mass index (BMI), waist circumference (WC) and waist-to-hip ratio $(\mathrm{W} / \mathrm{H})(4)$. BMI is a useful measurement of overall obesity. Whereas in order to determine central obesity, WC, which demonstrates the existence of abdominal visceral fat more accurately, is applied (5) and constitutes one of the diagnostic criteria of the metabolic syndrome $(6,7)$. The use of WC has certain limitations. First of all, it requires conditions such as unclothing and the convenience of ambient temperature. The second one is that it may vary throughout the day based on the fasting - satiety status. The third one is that it may vary in case of health problems which shall affect the abdominal wall, e.g. lipoabdominoplasty and dyspepsia. The fourth one is that some people may not allow the measurement with light clothes due to sociocultural reasons (8).

In recent years, neck circumference (NC), which is an easier and faster anthropometric measurement, has been defined to determine central obesity (9). In community-based studies, it has been demonstrated that there is a positive correlation between $\mathrm{NC}$ and metabolic risk factors, insulin resistance and visceral adipose tissue, and that it is an independent determinant for the cardiometabolic syndrome $(10,11)$. In addition, the correlation between central obesity and $\mathrm{NC}$ has also been demonstrated in different ethnic groups, diabetics and children (12-14). It is well established that the obesity degree is increasing with younger males and females (15). A correlation between NC and metabolic 
abnormalities has been demonstrated by Atabek et al. (16) in obese Turkish children, and by Onat et al. (17) in Turkish adults in all age groups. However, there is a lack of studies examining the association between $\mathrm{NC}$ and central obesity in younger subjects at the university age.

Because of the latter, it has been decided to conduct a study aimed at evaluating the correlation of the neck circumference with $\mathrm{BMI}, \mathrm{WC}, \mathrm{W} / \mathrm{H}$ ratio in young male and female (18-24 years of age) university students.

\section{MATERIALS AND METHODS}

A total of 1,777 students aged 18-24 years were included in the study. They were studying at Kurklareli University. The subjects were determined by "random" sampling. The sampling was made by choosing even-numbered students. The even-numbered students among those students, who were attending the school during the 30 days period of the measurements, were chosen. Written informed consent was obtained from all participants. This study complied with the Declaration of Helsinki (18). Past medical history was determined with a standardized questionnaire. Anthropometric measurements such as height, weight, waist circumference, hip circumference, and neck circumference were made.

Those not accepting to participate in the study $(n=350$ men, $\mathrm{n}=215$ women), those with thyroid disease $(\mathrm{n}=35)$, those with metabolic disorder except for obesity $(n=2)$, pregnant $(n=1)$, lactating women $(\mathrm{n}=1)$, those on medication for any reason $(n=5)$, body builders or professional/amateur athletes $(n=10)$, and physically handicapped persons $(n=1)$ were excluded from the study. As a result 1,157 (838 females, 319 males) of students were examined.

Measurements were obtained in light clothes, fasting, standing, without shoes and at the end of expiration. Weight was measured using digital scale to the nearest $0.1 \mathrm{~kg}$ with only undergarments, and height was determined using a portable stadiometer to the nearest $1 \mathrm{~mm}$ barefoot. Waist circumference was taken horizontally to the nearest $1 \mathrm{~mm}$, using plastic tape measure at midpoint between the costal margin and iliac crest in the mid-axillary line. Hip circumference was measured at the level of greater trochanters with the legs close together. Neck circumference was measured in the midway of the neck, between mid cervical spine and mid anterior neck, to the nearest $0.5 \mathrm{~mm}$, with non stretchable plastic tape. In men with a laryngeal prominence (Adam's apple), it was measured just below the prominence. While taking this parameter the subject was asked to look straight ahead, with shoulders down, but not hunched. BMI was calculated as weight (kilogramme) divided by the square of height (meter). W/H ratio was calculated by dividing the waist circumference by the hip circumference.

Overweight was defined as BMI $25-29.9 \mathrm{~kg} / \mathrm{m}^{2}$, obesity was defined as $\geq 30 \mathrm{~kg} / \mathrm{m}^{2}$ (19). Central obesity was defined as waist circumference $\geq 94 \mathrm{~cm}$ (men) and $\geq 80 \mathrm{~cm}$ (women) (20).

\section{Statistical Analysis}

SPSS 20.0 (Statistical Package for Social Sciences) software was used for data analysis. The significance of gender differences in the anthropometric variables was tested by using the Independent $t$ test and Pearson's correlation coefficient was used to explore the association between $\mathrm{NC}$ and other anthropometric variables by gender. All reported $\mathrm{p}$ values are 2-sided, and a $\mathrm{p}$ value of $<0.05$ was considered to be significant.

\section{RESULTS}

The sample group consisted of persons aged 18-24 years, with a weight of 40-120 kg, BMI varying between 15.3-49.4 $\mathrm{kg} / \mathrm{m}^{2}$. The anthropometric measurements of the participants by gender are presented in Table 1 . The 1,157 subjects had a mean age of $20.5 \pm 1.4$ years (men: $20.8 \pm 1.4$, women: $20.3 \pm 1.4$ years), a mean BMI of $24.7 \pm 6.4$ (men: $27.4 \pm 6.0$, women: $21.3 \pm 3,1$ $\mathrm{kg} / \mathrm{m}^{2}$ ), a mean WC of $83.6 \pm 18.6$ (men: $96.0 \pm 18.7$, women: $73.0 \pm 8.0 \mathrm{~cm}$ ), a mean $\mathrm{HC}$ of $101.7 \pm 12.8$ (men: $107.5 \pm 12.8$, women: $95.6 \pm 7.2 \mathrm{~cm}$ ), and a mean NC of $33.1 \pm 4.4$ (men: 35.6 \pm 7.2 , women: $30.6 \pm 1.9 \mathrm{~cm})$. All anthropometric measurements were significantly higher in men compared to women $(p<0.001)$. The prevalence of overweight was $5.8 \%$ for men and $5.5 \%$ for women. The prevalence of obesity was $10.3 \%$ for men and $12.4 \%$ for women. The prevalence of abdominal obesity was $13.5 \%$ for men and $15.4 \%$ for women.

The correlation between the neck circumference and the other anthropometric measurements by gender is shown in Table 2. In male subjects, $\mathrm{NC}$ revealed a positive correlation with $\mathrm{BMI}(\mathrm{r}=$ $0.684, \mathrm{p}<0.01)$, WC $(r=0.686, p<0.01)$ and $\mathrm{W} / \mathrm{H}$ ratio $(\mathrm{r}=0.534$, $\mathrm{p}<0.01$ ). Similarly, in female subjects NC revealed a positive

Table 1. Anthropometric measurement values of all participants by gender

\begin{tabular}{|l|c|c|c|}
\hline \multirow{2}{*}{ Variables } & Men $(\mathrm{n}=319)$ & Women $(\mathrm{n}=838)$ & \multirow{2}{*}{$\mathrm{p}$} \\
\cline { 2 - 4 } & Mean SD (range) & Mean SD (range) & $\mathrm{n}$ \\
\hline Age $($ year) & $20.8 \pm 1.4(18-25)$ & $20.3 \pm 1.4(18-25)$ & $<0.001$ \\
\hline Height $(\mathrm{m})$ & $1.75 \pm 0.08(1.55-1.96)$ & $1.63 \pm 0.05(1.48-1.79)$ & $<0.001$ \\
\hline Weight $(\mathrm{kg})$ & $83.9 \pm 17.2(52-138)$ & $57.1 \pm 8.7(40-95)$ & $<0.001$ \\
\hline Body mass index $\left(\mathrm{kg} / \mathrm{m}^{2}\right)$ & $27.4 \pm 6.0(17.5-49.4)$ & $21.3 \pm 3.1(15.3-39.1)$ & $<0.001$ \\
\hline Waist circumference $(\mathrm{cm})$ & $96.0 \pm 18.7(64-142)$ & $73.0 \pm 8.0(54-100)$ & $<0.001$ \\
\hline Hip circumference $(\mathrm{cm})$ & $107.5 \pm 12.8(84-153)$ & $95.6 \pm 7.2(72-126)$ & $<0.001$ \\
\hline Waist/hip ratio & $0.88 \pm 0.09(0.7-1.25)$ & $0.76 \pm 0.06(0.6-1.02)$ & $<0.001$ \\
\hline Neck circumference $(\mathrm{cm})$ & $35.6 \pm 7.2(29-51)$ & $30.6 \pm 1.9(25-38)$ & \\
\hline
\end{tabular}


Table 2. Relationship between NC and other anthropometric variables by gender

\begin{tabular}{|l|c|c|}
\hline \multirow{2}{*}{ Variables } & Men $(\mathrm{n}=319)$ & Women $(\mathrm{n}=838)$ \\
\cline { 2 - 3 } & $\mathrm{r}$ & $\mathrm{r}$ \\
\hline Body mass index $\left(\mathrm{kg} / \mathrm{m}^{2}\right)$ & $0.684^{*}$ & $0.482^{*}$ \\
\hline Waist circumference $(\mathrm{cm})$ & $0.686^{*}$ & $0.479^{*}$ \\
\hline Hip circumference $(\mathrm{cm})$ & $0.646^{*}$ & $0.556^{*}$ \\
\hline Waist/hip ratio & $0.646^{*}$ & $0.246^{*}$ \\
\hline
\end{tabular}

"Correlation is significant at the 0.01 level.

correlation with BMI $(\mathrm{r}=0.482, \mathrm{p}<0.01), \mathrm{WC}(\mathrm{r}=0.479, \mathrm{p}<0.01)$ and $\mathrm{W} / \mathrm{H}$ ratio $(\mathrm{r}=0.246, \mathrm{p}<0.01)$.

\section{DISCUSSION}

In this study, it has been demonstrated that the NC measurement may be used as an easy and fast method for the central obesity survey in young subjects at the university age. There was a significant and substantial correlation between the NC measurement and WC frequently used in establishing the metabolic syndrome and intraabdominal fat mass.

In the former studies, the correlation between obesity and metabolic disorders and cardiovascular risk factors has been established (11). Even though BMI, WC and W/H ratio are anthropometric indexes commonly used in the diagnosis of obesity, the number of publications stating that $\mathrm{NC}$ is an easier and faster parameter has been gradually increasing during recent years (9). The fact that the NC measurement is a fast method applicable to everyone and in every environment without being affected by fasting-satiety, garments, the ambient temperature, and sociocultural limitations, is an advantage. In a study by Zhou et al. (11) comprising 4,201 subjects (mean age: 43 years), a positive correlation has been established between NC and cardiometabolic risk factors - systolic blood pressure, diastolic blood pressure, glucose, triglyceride, total cholesterol, low density lipoprotein cholesterol (LDL-C), BMI and $\mathrm{WC}$, and a negative correlation to high density lipoprotein cholesterol (HDL-C). The positive correlation between NC, BMI and WC has been established by Yan et al. (21) in 2,092 elderly subjects ( $>65$ years), and by Yang et al. (22) in 3,182 diabetic subjects. Similar results have been observed in 1,912 Turkish subjects (mean age 55 years) (17). In our study, we have established that $\mathrm{NC}$ has shown a significant correlation with other anthropometric measurements (BMI, $\mathrm{WC}$ and $\mathrm{W} / \mathrm{H}$ ratio) in young men and women at the university age. Upon comparison of central obesity and subcutaneous fat accumulation, it is evident that there is more metabolic abnormality in those with central obesity (23). WC and $\mathrm{W} / \mathrm{H}$ ratio show the visceral fat accumulation better than BMI and has a substantial association with $\mathrm{NC}$ as well as metabolic disorders and indexes indicating visceral fat accumulation (24).

The cardiovascular disease risk with obesity varies from one community to another. Asians, for example, are more susceptible and thus BMI risk thresholds are lower than in other populations, with an action point for overweight defined at $23 \mathrm{~kg} / \mathrm{m}^{2}(25)$. Obesity, prediabetes and diabetes are causes of morbidity, disability and premature death in Turkey. Turkish people are more obese, more prediabetic/diabetic and have a wider waist circumference in comparison to other communities. The increased cardiovas- cular risk rate may be attributed to these factors. Therefore, it shall be important to survey and manifest the obese individuals at an early age.

Obesity, prediabetes and diabetes increase the risk for a wide range of chronic diseases. Obesity and insulin resistance is the beginning of these health problems. BMI is thought to account for about $60 \%$ of the risk of developing prediabetes and type 2 diabetes. The disability attributable to obesity are primarily consequences of ischaemic heart disease and type 2 diabetes. In a study by Onat et al. (17), the NC cut off values, which demonstrated a correlation with NC in terms of obesity and which are suggested for obesity, were 38.5 for men and 34.5 for women. Our study group consisted of $13.5 \%$ centrally obese men and $15.4 \%$ centrally obese women. The probable reason for the fact that this rate lies below the country's average is the low frequency of diabetes in this age group. Consequently, the awareness of a lifestyle change in this age group might be useful in reducing the number of prediabetes and diabetes cases occuring in the future years.

The present study has some limitations. First of all, since the study comprised university students aged 18-24 years, it may not reflect the entire society. Secondly, the study group consisted of students of just one university. However, the students attending this university come from different regions of the country. Thirdly, there is no established guideline for the prevention of faults related to the measurement technique.

For the determination of central obesity, the NC measurement is an easy and fast survey method. This method may be easily applied in order to create awareness of central obesity in young people aged 18-24 years. Since another method, namely waist circumference measurement, requires unclothing for women, it is hardly applicable due to social and cultural reasons. Besides, it has to be measured when fasting and after urination. Whereas another index, i.e. BMI, cannot reveal the difference of fat distribution between waist and hip.

\section{CONCLUSION}

The neck circumference measurement is a simple and substantial method which may be applied to reveal central obesity in Turkish subjects at the university age. It shall be useful to perform a simple NC measurement in university students in order to increase the awareness of central obesity. Setting cut-off values which demonstrate central obesity in university students requires new studies.

\section{Conflict of Interests}

None declared 


\section{REFERENCES}

1. Nutrition, physical activity and obesity: Turkey [Internet]. Geneva: World Health Organization, Regional Office for Europa; 2013 [cited 2015 May 21]. Available from: http://www.euro.who.int/_data/assets/ pdf file/0017/243332/Turkey-WHO-Country-Profile.pdf?ua=1 .

2. Satman I, Beyhan O, Tutuncu Y, Kalaca S, Gedik S, Dinçdag N, et al. Twelve-year trends in the prevalence and risk factors of diabetes and prediabetes in Turkish adults. Eur J Epidemiol. 2013 Feb;28(2):169-80.

3. Ilhan S, Yilmaz T, Sengül A, Salman S, Salman F, Uygur S, et al. Population-based study of diabetes and risk characteristics in Turkey results of the Turkish diabetes epidemiology study (TURDEP). Diabetes Care. 2002 Sep;25(9):1551-6.

4. Chan DC, Watts GF, Barrett PH, Burke V. Waist circumference, waistto-hip ratio and body mass index as predictors of adipose tissue compartments in men. QJM. 2003 Jun;96(6):441-7.

5. Pouliot MC, Despres J, Lemieux S, Moorjani, S, Bouchard, C, Tremblay A, et al. Waist circumference and abdominal sagittal diameter: best simple anthropometric indexes of abdominal visceral adipose tissue accumulation and related cardiovascular risk in men and women. Am J Cardiol. 1994;73:460-8.

6. Alberti KG, Zimmet P, Shaw J. Metabolic syndrome - a new world-wide definition. A Consensus Statement from the International Diabetes Federation. Diabet Med. 2006 May;23(5):469-80.

7. Esfarjani F, Khalafi M, Mohammadi F, Zamani-Nour N, Kelishadi R. Metabolic Syndrome and its determinants in a sample of young Iranian children with obesity. Pak J Med Sci. 2013;29(1 Suppl):253-57.

8. Wang J, Thornton JC, Bari S, Williamson B, Gallagher D, Heymsfield $\mathrm{SB}$, et al. Comparisons of waist circumferences measured at 4 sites. Am J Clin Nutr. 2003 Feb;77(2):379-84.

9. Aswathappa J, Garg S, Kutty K, Shankar V. Neck circumference as an anthropometric measure of obesity in diabetics. N Am J Med Sci. 2013 Jan;5(1):28-31.

10. Kumar NV, Ismail MH, Mahesha P, Girish M,Tripathy M. Neck circumference and cardio- metabolic syndrome. J Clin Diagn Res. 2014 Jul; $8(7): 23-5$.

11. Zhou JY, Ge H, Zhu MF, Wang LJ, Chen L, Tan YZ, et al. Neck circumference as an independent predictive contributor to cardio-metabolic syndrome. Cardiovasc Diabetol. 2013 May 16;12:76.

12. Hingorjo MR, Masood A, Mehdi A. Neck circumference as a useful marker of obesity: a comparison with body mass index and waist circumference. J Pak Med Assoc. 2012 Jan;62(1):36-40.

13. Misra A, Wasir JS, Vikram NK. Waist circumference criteria for the diagnosis of abdominal obesity are not applicable uniformly to all populations and ethnic groups. Nutrition. 2005 Sep;21(9):969-76.

14. Nafiu OO, Burke C, Lee J, Voepel-Lewis T, Malviya S, Tremper KK. Neck circumference as a screening measure for identifying children with high body mass index. Pediatrics. 2010 Aug;126(2):e306-10.
15. Ogden CL, Carroll MD, Kit BK, Flegal KM. Prevalence of childhood an adult obesity in the United States, 2011-2012. JAMA. 2014 Feb 26;311(8):806-14.

16. Atabek ME, Ozgur P, Kurtoglu S. Prevalence of metabolic syndrome in obese Turkish children and adolescents. Diabetes research and clinical practice. 2006; 72(3):315-32.

17. Onat A, Hergenç G, Yüksel H, Can G, Ayhan E, Kaya Z, et al. Neck circumference as a measure of central obesity: associations with metabolic syndrome and obstructive sleep apnea syndrome beyond waist circumference. Clin Nutr. 2009 Feb;28(1):46-51.

18. World Medical Association. World Medical Association Declaration of Helsinki: ethical principles for medical research involving human subjects JAMA. 2013 Nov 27;310(20):2191-4.

19. Clinical guidelines on the identification, evaluation, and treatment of overweight and obesity in adults: executive summary. Expert Panel on the Identification, Evaluation, and Treatment of Overweight in Adults. Am J Clin Nutr. 1998 Oct;68(4):899-917.

20. Alberti KG, Eckel RH, Grundy SM, Zimmet PZ, Cleeman JI, Donato K, et al. Harmonizing the metabolic syndrome: a joint interim statement of the International Diabetes Federation Task Force on Epidemiology and Prevention; National Heart, Lung, and Blood Institute; American Heart Association; World Heart Federation; International Atherosclerosis Society; and International Association for the Study of Obesity. Circulation. 2009 Oct 20;120(16):1640-5.

21. Yan Q, Sun D, Li X, Zheng Q, Li L, Gu C, Feng B. Neck circumference is a valuable tool for identifying metabolic syndrome and obesity in Chinese elder subjects: a community-based study. Diabetes Metab Res Rev. 2014 Jan;30(1):69-76.

22. Yang GR, Yuan SY, Fu HJ, Wan G, Zhu LX, Bu XL, et al. Neck circumference positively related with central obesity, overweight, and metabolic syndrome in Chinese subjects with type 2 diabetes: Beijing Community Diabetes Study 4. Diabetes Care. 2010 Nov;33(11):2465-7.

23. Dahlén EM, Bjarnegård N, Länne T, Nystrom FH, Ostgren CJ. Sagittal abdominal diameter is a more independent measure compared with waist circumference to predict arterial stiffness in subjects with type 2 diabetes - a prospective observational cohort study. Cardiovasc Diabetol. 2013 Mar 28;12:55.

24. Ben-Noun L, Sohar E, Laor A. Neck circumference as a simple screening measure for identifying overweight and obese patients. Obes Res. 2001 Aug;9(8):470-7.

25. World Health Organization. Obesity: preventing and managing the global epidemic: report of a WHO consultation. WHO technical report series; 894. Geneva: World Health Organization; 2000.

Received September 10, 2015 Accepted in revised form March 29, 2016 